\title{
Identidades de gênero no movimento funk: um estudo explanatório crítico de notícias jornalísticas brasileiras
}

\author{
Maria Carmen Aires Gomes* \\ Universidade Federal de Viçosa \\ Viçosa, MG, BR
}

\section{Resumo}

Neste artigo analiso as designações escolhidas pelos veículos Tititi, Site R7 e Site G1 para representarem as MC's Xuxu, Transnitta e Mulher Banana e as temáticas sobre pessoas trans, sexualidade e sexo, geradas em função da heterogeneidade textual e discursiva. Meu objetivo é problematizar a forma como as práticas midiáticas jornalísticas (tanto de revista, como de jornal) designam, denominam e atribuem vozes às MC's, que são mulheres trans corpos femininos generificados. Serão analisados três textos noticiosos extraídos da revista popular Tititi e dos sites R7 (Grupo Record) e G1 (Rede Globo de produções), que fazem parte de um corpus documental do projeto Corpo na mídia impressa e televisiva: representações de vulnerabilidade social e diferença na sociedade contemporânea. Os dados serão analisados à luz de uma proposta transdisciplinar que dialoga os princípios epistemológicos dos estudos discursivos críticos, em especial a proposta anglo-saxã de Norman Fairclough (2001; 2003), Chouliaraki e Fairclough (1999), e das pesquisas epistemológicas e ontológicas sobre identidades de gênero, sexualidade e sexo (LOURO, 2007; BUTLER, 2010, 2015; CESAR; 2014; BENTO, 2015a, BENTO, 2015b) e do debate sobre corpo como construto semiótico (LE BRETON, 2003, 2010, 2014).

Palavras-chave: ADC; Identidades de Gênero; Mídia; Corpo

\section{Gender identities in the funk movement: a critical explanatory study of Brazilian newspaper news}

\begin{abstract}
This article analyzes the designations chosen by the vehicles Tititi, R7 Site and Site G1 to represent the MC's $\mathrm{Xuxu}$, Transnitta and Banana Woman and the issues about trans people, sexuality and gender, generated on the basis of textual and discursive heterogeneity. My intention is to discuss how the journalistic media practices (both magazine and newspaper) designate, call and assign voices to MC's, who are women trans gendered female bodies. I will analyze three news texts in the popular magazine Tititi and site R7 (Record Group) and site G1 (Rede Globo productions), which are part of a documentary corpus of body design in print and broadcast media: social vulnerability representations and difference in contemporary society. The data will be analyzed in the light of a transdisciplinary proposal that dialogues with the epistemological principles of critical discourse studies, especially the Anglo-Saxon proposal by Norman Fairclough (2001, 2003), Chouliaraki and Fairclough (1999), and epistemological and ontological research on gender identities, sexuality and sex (LOURO, 2007; Butler, 2010, 2015; CESAR; 2014; BENTO, 2015th, BENTO, 2015b) and the debate on the body as a semiotic construct (LE BRETON, 2003 2010, 2014)
\end{abstract}

Keywords: Body, Gender Performativity, Cda, Media

\footnotetext{
* Maria Carmen Aires Gomes é professora associada II, do Departamento de Letras da Universidade Federal de Viçosa, onde atua no Programa de Pós-graduação em Letras, na área de Estudos Discursivos. É professora colaboradora do Programa de Pós-graduação em Estudos Linguísticos na Faculdade de Letras da UFMG/ MG, atuando como orientadora de doutorado em estudos do discurso. É doutora em Estudos da Linguagem e Linguística Aplicada pela PUC/SP. Seus interesses de pesquisa centram-se em estudos discursivos críticos em interface com os estudos sobre corpo, identidades de gênero e práticas midiáticas. mcgomes@ufv.br
} 


\section{Considerações iniciais}

É impossível pensarmos o corpo fora das vivências culturais e sociais, das nossas práticas políticas, ou seja, sem levar em conta a historicidade e a nossa vida social. Essa compreensão da corporeidade como fenômeno social e cultural é debatida pelos estudos desenvolvidos pela Sociologia do Corpo (cf. DAVID LE BRETON, 2003, 2010, 2014), que tem como premissa o fato de que o corpo é o local de mediação entre as pessoas e o mundo, é o que permite a constituição de nossa individualidade e a formação de nossas identidades; por isso, a corporeidade é tanto um espaço de inclusão quanto de exclusão sociocultural e política. O corpo é assim uma construção sociosemiótica, já que se constrói e se reconstrói constantemente e está sempre em movimento, reacentuando-se, reencenando-se. Neste sentido, "o corpo não é uma superfície pronta à espera de significação, mas um conjunto de fronteiras individuais e sociais, politicamente significadas e mantidas" (BUTLER, 2010, p. 59); torna-se, portanto, "uma fronteira variável, uma superfície cuja permeabilidade é politicamente regulada, uma prática significante dentro de um campo cultural de hierarquia do gênero e heterossexualidade compulsória, então que linguagem resta para compreender essa representação corporal [...]" (BUTLER, 2010, p.198).

Podemos supor, então, que nós, sujeitos, realizamos ativamente o entrecruzamento das significações e potencialidades do mundo cultural ao nosso corpo, como resultado de um constante projeto político discursivo, executado por meio de atos performativos, que geram potencialidades generificadas, capazes de subverter as estruturas e dispositivos de poder existentes (SALIH, 2012). Butler (2010, p. 199) afirma então que "as possibilidades históricas materializadas por meio dos vários estilos corporais nada mais são do que ficções culturais punitivamente reguladas, alternadamente incorporadas e desviadas sob coação."

Se a nossa existência como indivíduo é corporal, portanto, cultural, histórica e sociosemioticamente construída, então nossas identidades são formadas por meio de "comportamentos normativos repetitivos, que Judith Butler chama de iterações performativas"
(BORGERSON, 2009, p .61). Ou seja: "os vários atos de gênero criam a ideia de gênero, e sem esses atos, não haverá gênero algum, pois não há nenhuma 'essência' que o gênero expresse ou exteriorize, nem tampouco um ideal objetivo ao qual aspire e porque o gênero não é um dado da realidade." (BUTLER, 2010, p. 199). Com essa problematização, Butler (2010) afirma que as identidades se formam e se produzem a partir das repetições regularizadas e constrangidas de comportamentos, atitudes, práticas e atos performatizados. Essas iterações performativas agem de maneira tão natural e hegemônica que criam modelos identitários ficcionais e ilusórios (ideal aparente), excluindo assim aqueles que não se adéquam aos padrões dos dispositivos da biopolítica e seus regimes de verdade (FOUCAULT, 20).

Assim que, para Judith Butler, "essa repetição não é realizada por um sujeito, mas o capacita, e constitui a condição temporal para o sujeito" (BORGERSON, 2009, p. 61). "Essa repetição é a um só tempo reencenação e nova experiência de um conjunto de significados já estabelecidos socialmente; e também é a forma mundana e ritualizada de sua legitimação." (BUTLER, 2010, p. 200). Dessa forma, "se a base da identidade de gênero é a repetição estilizada de atos ao longo do tempo, e não uma identidade aparentemente sem suturas, então a metáfora espacial de uma 'base' é deslocada e se revela como uma configuração estilizada, a rigor, uma coprorificação do tempo com marca de gênero" (BUTLER, 2010, p. 201). Ou seja: as identidades se formam ao longo do tempo e pelos constrangimentos de certas performances repetidas e regularizadas social, cultural, e discursivamente. Em função de tantas repetições, de tantos comportamentos, gestos, posturas, atos de fala regularizados, temos a impressão de que somos assim mesmo, ou que sabemos quem o outro é, ou significa. No entanto, é nessa exigência, neste comportamento restringido e constrangido, que as diferenças, os desvios e a subversão surgem; ou seja, há uma atualização de práticas com outros gestos, posturas, comportamentos, novas estilizações que produzem e formam Outridades (BENTO, 2015a).

As alterações, atualizações, substituições, deslocamentos e anulações ocorrem na medida em que compreendemos a singularidade do ser "livre", embora, 
como foi dito, constrangidos/as pelos dispositivos e seus regimes de verdade da biopolítica e seus ordenamentos. Para Foucault (2011 [1980]) apud BIRMAN, 2015, p. 47), essa liberdade significa dizer que "sujeitos individuais ou coletivos tem diante de si um campo de possibilidade ou diversas condutas -, diversas reações e diversos modos de comportamento podem ocorrer." Ou seja: onde o poder pode se deslocar e, no limite, escapar, está a renitência do querer e a intransitividade da liberdade". Butler (2011, p.22) afirma que o poder não é estático, nem estável, mas "se refaz nas diversas conjunturas da vida cotidiana”.

No entanto, é importante compreendermos que somos corpos constrangidos e marcados pelas práticas sóciohistóricas e culturais vivenciadas por nós. Não somos dados a priori, e nossas identidades não são estáticas, preexistentes, nem mesmo os diferentes são sempre diferentes, e nem sempre as fronteiras permanecem como estão (LE BRETON, 2010). Essa perpecpção se coaduna à ideia de que nossa vida social é aberta, e que portanto há uma diversidade de identidades, de corpos, de formas de viver, de agir e de pensar, regulados por mecanismos e dispositivos de poder (CHOULIARAKI \& FAIRCLOUGH, 1999), cabendo, portanto, a nós olharmos para as questões que envolvem sexualidade, sexo e gênero de uma maneira menos essencialista, hierárquica e atributiva, pautada nas práticas discursivas da biomedicina, e mais Queer, emancipatória. $\mathrm{Na}$ bordagem Queer, o gênero, como se percebe, "é radicalmente independente de sexo" (SALIH, 2012, p.71), já sexo "é uma significação performativamente ordenada (e portanto não "e’" pura e simplesmente), uma significação que, liberta da interioridade e da superfície naturalizadas, pode ocasionar proliferação parodística e o jogo subversivo dos significados do gênero" (BUTLER, 2010, p.59-60). A sexualidade refere-se às práticas erótico-sexuais, ao desejo, à atração. Neste artigo, alinho-me a estas problematizações para analisar a forma como as práticas midiáticas formam as identidades de gênero das funkeiras de maneira a demonstrar essa descontinuidade entre sexo, sexualidade e gênero.

Chouliaraki e Fairclough (1999, p.02), discutindo o foco pós-moderno da diferença e da contingência da vida social, afirmam que a pluralidade e a fragmentação da vida social moderna têm sido focadas na literatura da pós-modernidade com ênfase na diferença social. Neste mundo plural, o reconhecimento da diferença é crucial, imperativo, já que uma intervenção política efetiva por cidadãos depende de diálogos construídos por meio das diferenças na esfera pública, nos mais variados níveis: locais, regionais e globais. No entanto, os pesquisadores chamam a atenção para o fato de que diálogo não necessariamente prevê consenso, mas entrecruza diferentes vozes, alianças, aceitações, vozes que não suprimem a diferença de corpos padronizados, naturalizados, mas que emergem como uma voz em comum em questões específicas.

Fato é que, muitas vezes (ou na sua grande maioria), as representações da vida social nas construções discursivas e semióticas não passam de traduções seletivas, condensações e simplificações de determinadas narrativas socioculturais e políticas, naturalizadas pelas ações e práticas sociais. O trabalho discursivo-crítico permite compreender que a contestação e lutas de resistência contra ações, práticas e estratégias sociopolíticas e culturais são parte da contestação e lutas sobre construções discursivas, que buscam desvelar simplificações e seletividades (CHOULIARAKI E FAIRCLOUGH, 1999; FAIRCLOUGH E FAIRCLOUGH, 2012), responsáveis pelos obstáculos que impedem a transformação social. Problematizando os conceitos de hegemonia, contingência e universalidade, Butler (2011) afirma que "a transformação social não ocorre apenas reunindo massas em favor de uma causa, mas precisamente por meio das formas que as relações sociais cotidianas são rearticuladas, e novos horizontes conceituais são abertos por práticas anômalas e subversivas." Nesta esteira, Jurgen Habermas (1962), em Mudança estrutural da esfera pública, afirma que a sociedade moderna depende da capacidade de criticar e questionar coletivamente as nossas tradições, ou seja, precisamos problematizar a construção do consenso, de forma a pensar na mudança/transformação como forma de fortalecer a vida social.

É neste contexto que Butler (2010, p.8) problematizará as categorias de gênero que sustentam a hierarquia de gêneros e a heterossexualidade compulsória, e para tanto argumentará que identidades são formadas por atos performativos, discursivamente, que produzem 
corpos no interior das categorias de sexo, tornando-os "naturais e originais". Há assim uma presunção político-cultural de que há uma universalidade e unicidade genérica, ou uma construção binária estanque e estática do ser homem e ser mulher, tornando explícito o equívoco de se pensar que há uma "ilusão de uma substancialidade prévia, e a interpretação dos efeitos do ritual performático do gênero como emanações necessárias ou consequências causais desta substância prévia" (BUTLER, 2011, p.37).

Neste artigo analiso as designações escolhidas pelos veículos Tititi, Site R7 e Site G1 para representarem as MC's Xuxu, Transnitta e Mulher Banana e as temáticas sobre transgeneridade, sexualidade e sexo, geradas em função da heterogeneidade textual e discursiva. Meu objetivo é problematizar a forma como as práticas midiáticas jornalísticas (tanto de revista, como de jornal) designam, denominam e atribuem vozes às MC's, que são mulheres trans tratadas e representadas na maioria das vezes como corpos abjetos, uma vez que subvertem a matriz heterossexual e compulsória. Serão analisados três textos noticiosos extraídos da revista popular Tititi e dos sites R7 9 (Grupo Record) e G1 (Rede Globo de produções), que fazem parte de um corpus documental do projeto Corpo na mídia impressa e televisiva: representações de vulnerabilidade social e diferença na sociedade contemporânea. $\mathrm{O}$ objetivo deste projeto (PQ2/CNPq) era problematizar (colocar em xeque) os discursos formadores, universalizantes, hegemônicos, que constroem e constrangem o sujeito corpóreo que foge à matriz compulsória e hierárquica; o que denomino como corpo diferente. De forma a compreender a construção desse corpo diferente/excluído e marginalizado pelas práticas midiáticas televisivas, digitais e impressas, foram selecionados dados que foram sistematizados em duas grandes amostras discursivas, que compuseram o corpus documental proposto: Amostra 1 - Diferença - relações entre saúde, boa forma, beleza e corpo diferente (gordo, deficiente, idoso, "imperfeições físicas”, ou seja, corpo orgânico), e Amostra 2 - Diferença - relações entre gênero, sexualidade e sexo (corpo diferente, que não atende à matriz hegemônica heterossexual atributiva, hierárquica e binária, denominado como abjeto, monstro, patológico). Infelizmente, os resultados alcançados pelas pesquisas desenvolvidas no escopo do referido projeto (GOMES, 2013; SOUZA \& GOMES, 2013; ARAÚJO, 2014; PESSOA, 2015; RODY E GOMES, 2015; GOMES, 2014a; GOMES, 2014b, GOMES, 2014c, GOMES, 2015a, GOMES, 2015b, GOMES, 2015c), no âmbito da Amostra 2, nos levam a acreditar que as práticas midiáticas embora estejam dando visibilidade às Outridades - travestis, mulheres trans, homens trans, gays, lésbicas, transgêneros - nos mais variados veículos de comunicação, tal visibilidade é bastante perversa, pois tais práticas reduzem, simplificam e ironizam, muitas vezes, as questões sobre gênero, sexualidade e sexo. Há uma visível simplificação no trato da informação, gerando, na maioria das vezes, confusões conceituais graves e falaciosas.

$\mathrm{Na}$ primeira seção, apresentarei alguns princípios que norteiam os estudos discursivos críticos, em especial a abordagem discursiva textualmente orientada tal como desenvolvida por Norman Fairclough. Na segunda, justifico a escolha do objeto, a sistematização da amostra discursiva e apresento o enquadre metodológico e as categorias analíticas. Em seguida, as análises são realizadas por meio de excertos a fim de refletirmos de forma explanatória e crítica acerca do modo como as práticas midiáticas têm representado as Outridades, em especial as transmulheres.

\section{Análise discursiva textualmente orientada: das facetas discursivas às práticas midiáticas}

A Análise discursiva textualmente orientada (ADTO) tem um caráter posicionado, crítico, emancipatório, que busca não só a descrição linguístico-textual minuciosa de um documento-objeto, mas também a interpretação explanatória crítica dos fenômenos sociopolíticos, que se apresentam em instituições sociais, com determinadas formações ideológico-discursivas, e as respectivas relações de poder entre elas.

Sobre a agenda política e o trabalho crítico, Fairclough (1985, p. 747) diz que "em questões humanas, as interconexões e as redes de causa e efeito podem ser distorcidas a ponto de saírem do campo de visão. Assim, a atividade crítica consiste, essencialmente, em tornar visível a natureza interligada das coisas". Para Re- 
sende (2009, p. 12), a abordagem faircloughiana aponta que "pesquisas discursivas críticas estejam baseadas na identificação de problemas sociais parcialmente discursivos que possam ser investigados por meio da análise situada de textos". A principal tarefa dos estudos discursivos críticos é então mapear conexões entre semiose e sociedade, com o objetivo de, primeiro, localizar mecanismos semióticos, e suas causas e efeitos de sentido potencialmente ideológicos, para, em seguida, suscitar possíveis maneiras de superar relações assimétricas de poder parcialmente sustentadas pela linguagem.

$O$ foco da ADTO é discutir o engajamento na prática social e as mudanças requeridas, além de evidenciar os obstáculos para que ocorra esta mudança (CHOULIARAKI; FAIRCLOUGH, 1999). Para Resende (2009, p. 13) o "objetivo das análises é a crítica social obtida por meio da análise de instanciações discursivas que servem de subsídio e sustentação à crítica de problemas sociais." É preciso que expliquemos como certas práticas sociais produzem e/ou reproduzem principalmente construções discursivas capazes de deslegitimar, excluir ou marginalizar aquilo que não é aceito como "natural, normal, ou hegemônico". O trabalho ético (e crítico) busca, como aponta Souza Santos (2000), expor as inconsistências, contradições e dilemas, já que todo pensamento crítico é centrífugo e subversivo na medida em que visa criar desfamiliarização em relação ao que está estabelecido e convencionalmente aceito.

O objetivo das pesquisas é a crítica social obtida por meio da análise de instanciações discursivas que servem de subsídio e sustentação à crítica de problemas sociais (Resende, 2009). A relação entre práticas sociais e ordens do discurso e o foco na estruturação social das práticas implica que os recursos e constrangimentos das estruturas sociais também incidem sobre a estruturação do potencial semiótico, e essa estruturação tem efeito na configuração dos eventos discursivos (GIDDENS, 1991; RESENDE, 2009, p. 37). Dessa forma, estruturas, eventos e práticas têm um aspecto semiótico, que os fazem ser compreendidos, respectivamente como: ordem do discurso, textos e práticas de agir, ser e representar (gênero, estilo e discurso). Assim, campos sociais, instituições e organizações são constituídos por múltiplas práticas sociais, e suas redes de práticas são semioticamente as ordens do discurso (FAIRCLOUGH; FAIRCLOUGH, 2012).

Neste sentido, nosso objetivo neste artigo é tentar compreender como os textos midiáticos naturalizam as relações de poder, tecendo significados em construções discursivas aparentemente adequadas às instituições e às estruturas a que se vinculam, a fim de posicionarem os leitores/as em construções discursivas particulares. Dessa forma, alguns aspectos discursivos, em práticas sociais contextualizadas, podem implicar legitimação de ações particulares e determinar modos de conduta e atitudes. Isso ocorre porque textualmente podemos construir/representar/imaginar o mundo social em perspectivas específicas, particulares (FAIRCLOUGH, 2003 , p. 8), tratando-se, segundo o autor, de um processo de "meaning-making", que interferirá nos efeitos sociais dos textos.

A Linguística Sistêmico-Funcional (LSF) ${ }^{1}$ se coloca como teoria de base para os estudos discursivos críticos porque é multifuncional e tem como unidade semântica o texto. Além disso, busca compreender a relação entre linguagem e contexto social. Um dos pontos fortes da LSF é a capacidade de refletir sobre as relações de poder por meio da análise detalhada de textos: orações instanciadas em contextos sociais de uso da linguagem. ${ }^{2}$ Dessa forma, a dimensão do significado é central para a análise das desigualdades e vulnerabilidades sociais, pois nos permite perguntar: Quem está agindo? Quê tipo de ação, quem ou o quê está agindo? Está agindo de acordo com quem? Os estudos sistêmicos se mostram pertinentes pelo fato de o escopo analítico ser o texto, que é observado de duas perspectivas diferentes: a da potencialidade (aquilo que pode significar) e a da instância (o que significa numa situação particular).

O interesse da ADTO se motiva pelo importante papel da linguagem na vida social (principalmente, após a virada linguística, nos anos 60). Não é difícil pensarmos que nossa vida está cada vez mais mediada por textos, e que o papel de textos na vida social é cada vez mais saliente em todos os campos da atividade humana, como, por exemplo, a política, a economia e a cultura (CHOULIARAKI; FAIRCLOUGH, 1999). Para Fairclough (2003, p. 14), os textos têm consequências e efeitos sociais, políticos, cognitivos, morais e mate- 
riais, e, portanto, "é vital compreender esses efeitos se pretendemos levantar questões políticas e morais a respeito das sociedades contemporâneas [...]". Fairclough e Fairclough (2012) afirmam que a vida social pode ser analisada e conceptualizada como uma ação recíproca entre três níveis da realidade social: estruturas, práticas e eventos. As estruturas e eventos são mediados pelas práticas que são relativamente estáveis e duráveis e se constituem nas formas de agir, representar e ser associadas às identidades e discursos particulares. Esta relativa estabilidade deve-se ao fato de estruturas e ações serem dinâmicas, possibilitando a (re)produção de horizontes de expectativas, que podem se excluir, mas também se potencializar.

Chouliaraki e Fairclough (1999) argumentam que é no quadro das instituições e estruturas sociais que as práticas têm relativa permanência, já que estão expostas às mudanças e às transformações dos modos de ação produzidas por aquelas. As práticas então podem significar experiências com base em perspectivas particulares. No entanto, como bem pontua Fairclough (2001, p.93), "A constituição discursiva da sociedade não emana de um livre jogo de ideias nas cabeças das pessoas, mas de uma prática social que está firmemente enraizada em estruturas sociais materiais, concretas, orientando-se para elas." A ênfase na agenciação merece destaque porque frequentemente as identidades são constituídas por discursos institucionais que podem ser alvos de discursos globalizantes, pois se relacionam com outros discursos na ordem do discurso, no entanto temos de pensar que embora sejamos constrangidos pelas estruturas, temos de fortalecer nossa capacidade de não só nos auto-avaliarmos continuamente, mas também às práticas sociais decorrentes das estruturas (Cf. ARCHER, 2000).

Discutindo a relação entre agência e estrutura, Fairclough (2003, p.121) afirma que "os sujeitos são posicionados ideologicamente, mas também são capazes de agir criativamente no sentido de realizar suas próprias conexões entre as diversas práticas e ideologias a que são expostos e de reestruturar as práticas e as estruturas posicionadoras". Essa afirmação faircloughiana é respaldada não só pelas reflexões e discussões empreendidas por Anthony Giddens sobre o papel dos agentes na reprodução da estrutura, mas também pelo conceito de "relações posição-práticas" de Roy Bhaskar (1979) - também adotado por Giddens (1991). Para Giddens, os agentes sociais podem "fazer uma diferença" na reprodução da estrutura mesmo que de forma inconsciente, uma vez que toda reprodução é contingente e histórica; ou seja, segundo o sociólogo, não há garantia que os agentes irão reproduzir as condutas e comportamentos como o fizeram anteriormente. Assim, os agentes podem agir de forma diferente como sempre o fazem; podem se reelaborar. O conceito de posição-práticas refere-se, nessa reflexão, aos modos de condutas "esperados" de determinadas identidades, à "clausura" de determinadas relações sociais (Cf. COHEN, 1999, p.439-440).

Um dos diálogos possíveis entre os estudos Queer (BUTLER, 2010, 2015), e os estudos/ativistas transviados (BENTO, 2015a, 2015b) e a ontologia do discurso proposta por Chouliaraki e Fairclough (1999) para o estudo de identidades de gêneros e práticas midiáticas passa necessariamente pela centralidade e importância dos conceitos de discurso e de sua relação dialética com outras facetas do social e de prática social. O princípio discursivo-crítico de que o discurso é um elemento da prática social, portanto, constituinte das formações, naturalizações e transformações identitárias, se coaduna às discussões de Bento (2015b, p. 145) sobre a necessidade de pensarmos sobre a relação entre estruturas, práticas socioculturais e históricas e ação: "se é na prática que o gênero se faz, eu preciso entender como se estruturam as práticas de outras sociedades ou mesmo em nossa cultura."

Se para Fairclough (2003, p.159) "Quando diferentes discursos entram em conflito e discursos particulares são contestados, o que é contestado é o poder destes sistemas semânticos pré-construídos que geram visões particulares do mundo que podem ter o poder performativo para sustentar ou refazer o mundo à sua imagem, por assim dizer" (FAIRCLOUGH, 2003, p. 130), para Butler, "se os atributos e atos do gênero, as várias maneiras como o corpo mostra ou produz sua significação cultural, são performativos, então não há identidade preexistente pela qual um ato ou atributo possa ser medido; não haveria atos de gênero verda- 
deiros ou falsos, reais ou distorcidos, e a postulação de uma identidade de gênero verdadeira se revelaria uma ficção reguladora."(BUTLER, 2010, p. 201), então, parece-nos ter uma linha espistemológica e ontológica comum de que se os discursos constituem identidades. Então estas só se formam em função do poder performativo que pode sustentar, naturalizar e/ou subverter normas, padrões e injunções. Neste sentido, a identidade de gênero "é uma espécie de imitação persistente, que passa como real" (BUTLER, 2010, p. 9). Essa imitação, definida como performativa por Butler, sutenta ou desestabiliza os discursos que operam sobre o gênero. Para Butler (2010, p. 208), "compreender a identidade como uma prática, e uma prática significante, é compreender sujeitos culturalmente inteligíveis como efeitos resultantes de um discurso amarrado por regras, e que se insere nos atos disseminados e corriqueiros da vida linguística." Há assim uma relação "dialética", ou constitutiva, entre formação identitária de gênero e discursos: nos formamos pelo e no discurso, de maneira performativa, o que implica dizer que não somos predeterminados por regras, normas, mas regulados por atos performativos, pela repetição, iteração que tanto pode sustentar as normas, quanto desestabilizá-las, compelidas por sanção social e tabu.

Dessa forma, tanto para Chouliaraki e Fairclough quanto para Butler, as identidades são atos de criação linguística, produzidas pelas discursividades. Isso quer dizer que as ações éticas não são nem totalmente determinadas, nem radicalmente livres; o sujeito luta cotidianamente entre os constrangimentos da norma e sua capacidade de ação. Segundo Butler (2015, p. 31), "a injunção força o ato de criar a si mesmo ou engendrar a si mesmo, ou seja, ela não age de maneira unilateral ou determinística sobre o sujeito", pois, é por meio da norma, da injunção, que o sujeito inaugura sua reflexividade." Tanto para Chouliaraki e Fairclough (1999) quanto para Butler (2015), a operação crítica necessita, assim, de uma dimensão reflexiva, pois, ao questionar o regime de verdade, "questionase também o regime pelo qual se atribuem o ser e a própria condição ontológica" (p. 35).

A relação entre práticas sociais e ordens do discurso e o foco na estruturação social das práticas im- plica que os recursos e constrangimentos das estruturas sociais também incidem sobre a estruturação do potencial semiótico, e essa estruturação tem efeito na configuração dos eventos discursivos. (RESENDE, 2009, p. 37). Dessa forma, estruturas, eventos e práticas têm um aspecto semiótico, que os fazem ser compreendidos, respectivamente, como: ordem do discurso, textos e práticas de agir, ser e representar (gênero discursivo, estilo e discurso). Assim, campos sociais, instituições e organizações são constituídas por múltiplas práticas sociais e suas redes de práticas são semioticamente as ordens do discurso (FAIRCLOUGH; FAIRCLOUGH, 2012).

Tomo como ponto de partida a ideia de que as pessoas imersas nas práticas midiáticas fazem escolhas "sobre o modelo e a estrutura de suas orações que resultam em escolhas sobre o significado de identidades sociais, relações sociais e conhecimento e crença" (FAIRCLOUGH, 2001, p. 104). O objetivo aqui é mapear "escolhas linguísticas em contextos sociais amplos, a fim de desenvolver uma compreensão acurada do funcionamento social da linguagem" (RESENDE, 2009, p. 47). Ou seja: procuro explicar criticamente como as práticas midiáticas ao escolherem certos elementos lexicogramaticais e textuais potencializam relações de poder acerca das problematizações referentes às identidades de gênero. Dessa forma, ao designarem as funkeiras ora como travestis, ora como transexuais, ora na desinência feminina, ora na masculina, os textos midiáticos estão estilizando corpos e produzindo gêneros desviantes, dissidentes da ordem compulsória (BORBA, 2014).

\section{Ponto de partida do corpus e os procedimentos metodológicos}

Alinhando-me às ideias de Resende (2009, p. 79), meu objetivo é analisar o momento discursivo (ou os momentos discursivos) das práticas midiáticas jornalísticas e "as relações causais que estabelecem com outros momentos das práticas, as relações de emergência entre aspectos discursivos e não-discursivos na reprodução e transformação da sociedade". Busco analisar não só como as construções discursivas sobre sexo, gênero, se- 
xualidade e transexualidade se entrecruzam de forma a manter/transformar a visão sobre Outridades, mas também como as representações entram em conflito nas práticas midiáticas jornalísticas, gerando contradições que bloqueiam a ação social/agência transformadora e emancipatória (RESENDE, 2009, p. 82).

$O$ foco central dessa pesquisa é refletir sobre o corpo diferente, partindo do princípio que todo pensamento crítico é centrífugo e subversivo na medida em que visa criar desfamiliarização em relação ao que está estabelecido e convencionalmente aceito (SOUZA SANTOS, 2000). O propósito aqui é refletir sobre a forma como as notícias midiáticas tratam o corpo compreendido como diferente, aquele que não atende aos padrões hegemônicos da matriz heterossexual. A análise partiu da percepção do problema (corpo de mulheres trans retratado como diferente da heterossexualidade compulsória), relacionado às praticas midiáticas digitais e impressas, (CHOULIARAKI \& FAIRCLOUGH, 1999, p. 60); em seguida, verificamos quais são os obstáculos para que o problema seja superado ou se torne mais visível - quais as características permanentes nas redes de práticas midiáticas que sustentam o problema observado - por meio de três focos de análise correlacionados: análise da conjuntura, análise da prática particular midiática e, finalmente, a análise de discurso.

Estou analisando a midiatização do corpo da mulher trans pelo fato de ser um dos tipos de feminilidades, e se o feminino sempre esteve submetido ao modelo do patriarcado, ao masculino, construindo-se na narrativa da diferença. Então, o meu pressuposto é o de que o corpo/identidade da mulher trans também será afetado pelos discursos de binarismo de gênero, ou seja, pelo determinismo biológico. Bento (2015a, p. 14), refutando a tese de que a verdade de nós mesmos estaria em algum lugar do corpo, relata que "Muitas vezes escutamos: 'nossa, mas é igualzinha a uma mulher', para se referir à mulher trans. Entretanto, afirma a pesquisadora: "Ela não é igualzinha. Ela é uma mulher, porque assim ela vive seu gênero." Argumenta ainda que esses deslocamentos acontecem diariamente com pessoas trans que "fazem gênero desfazendo gênero, ou seja, se atualizam em suas práticas determinadas estilísticas que fogem do binarismo" (BENTO, 2015a, p. 14). São esses movimentos que vulnerabilizam e excluem politicamente esses corpos, pois se fundamentam apenas nos marcadores da biomedicina. Por isso, investigar tais corpos midiatizados torna-se um problema parcialmente discursivo importante a ser analisado, pois é preciso que problematizemos e neguemos "o primado dos cromossomos, dos neurônios e dos hormônios na definição de quem somos" (BENTO, 2015a, p. 13), constantemente reforçados, principalmente pelas práticas midiáticas.

O conceito de escolha, então, é significativo, pois ao observarmos o que está sendo excluído, e o que está sendo incluído, o que está sendo tematizado e o que não está tematizado (HALLIDAY; MATHIESSEN, 2004; FAIRCLOUGH, 1995, 2003) nas práticas midiáticas podem nos dizer muito acerca das representações que envolvem as relações entre sexo, sexualidade e gênero, pois, ao escolher certas designações, desinências nominais e atributos, as práticas midiáticas estão agindo, formando gêneros, pois estes se constroem, se sustentam e se transformam nas construções discursivas. Considerando que as escolhas se relacionam às ciscunstâncias, propósitos e investimentos ideológicos, Fairclough (1995, p. 105) questiona quais seriam as motivações dessas escolhas em termos de "representação, significação e construção.

Fairclough (1995, p. 103) argumenta então que os textos midiáticos não são meramente espelhos de realidades como alguns supõem, mas constituem versões de realidades, pois dependem das posições sociais, interesses e objetivos daqueles que os produzem. Compreender as relações entre a ordem do discurso midiática e suas práticas no escopo da esfera pública não é uma tarefa tão simples, já que muitas variáveis se entrecruzam nesta relação, pois as práticas discursivas midiáticas são atravessadas por outras práticas e ações decorrentes de outras instituições e ordenamentos discursivos. Para Fairclough (1995, p. 60), "a heterogeneidade textual pode ser compreendida como uma materialização das contradições sociais e culturais e como uma importante evidência para a investigação destas contradições e sua evolução." Segundo Fairclough (1995, p. 106) a relação entre presença e ausência de informações, conhecimentos, é construída em graus variados que vai da ausência, 
pressuposição, segundo plano, até a informação dada em primeiro plano.

Considerando que os veículos midiáticos escolhidos para este estudo se diferenciam não só em relação às práticas de produção, consumo e circulação, mas também em termos de investimentos ideológicos, uma vez que têm valores institucionais distintos, de forma sintética, apresento-os, abaixo:

- Revista Tititi - é uma produção do grupo PubliAbril e se classifica com femininas populares. Tem como slogan: O mundo da TV em suas mãos. "Os bastidores da vida dos famosos". A missão da publicação, segundo site da PubliAbril ${ }^{3}$, e ser a espiã da leitora no mundo das novelas, da TV e dos famosos. De circulação semanal, tematiza fatos e acontecimentos relacionados à televisão. Destacam-se os resumos das telenovelas e a "vida pública e privada de celebridades, com maior importância para atrizes e atores em destaque no momento é relevante"'.

- $\quad R 7$ - "É o site da Rede Record, rede de televisão aberta brasileira fundada por Paulo Machado de Carvalho, em1953. A partir de 2007, se consolidou como a segunda rede de TV de maior audiência no Brasil. Hoje, é a $28^{\circ}$ maior emissora de TV comercial do mundo. No final da década de 1980, o canal, que antes pertencia a Paulo Machado de Carvalho e Silvio Santos, foi comprado pelo empresário e religioso Edir Macedo, fundador da Igreja Universal do Reino de Deus. A Missão da empresa é produzir informação com imparcialidade e credibilidade, além de oferecer entretenimento de qualidade e prestar serviços à sociedade, contribuindo para a formação de cidadãos críticos e atuantes."

- G1 - "Documentar o dia-a-dia da diversidade cultural do povo brasileiro faz parte e uma das missões da Rede Globo. Segundo informações do Institucional da Globo ${ }^{6}$, ela é o espelho que reflete a nossa cultu$r a$, a janela que mostra aos outros povos as cores do Brasil e através da qual se vê o Brasil e o mundo. No jornalismo, além do espaço ocupado pela pauta social e a busca por isenção e objetividade, reportagens exibidas nos telejornais são dedicadas à investigação e ao aprofundamento de temas sociais relevantes. $\mathrm{Na}$ área de entretenimento, a opção pela teledramaturgia nacional, baseada na diversidade do Brasil, é resultado dessa vocação."

Pode-se dizer que esferas e instituições sociais podem determinar algumas estratégias em função dos recursos linguístico-discursivos empregados, mas não restringi-las. Enquanto umas práticas institucionais selecionam estratégias mais flexíveis e abertas, outras restringem suas ações e interações sociais. Isso implica dizer que, em cada prática midiática, teremos agentes sociais com capacidade e poder distintos de forma a gerar discursos mais ressonantes capazes de mobilizar um número maior de pessoas. $\mathrm{O}$ fato é que cada empresa jornalística selecionará elementos lexicogramaticais, textuais e discursivos específicos para atrair seus possíveis leitores/leitoras.?

As categorias utilizadas para a análise linguísticodiscursiva são o Sistema de Transitividade (como as funkeiras são representadas por meio de participante, processo e circunstância? Como a transgeneridade é representada e avaliada? (HALLIDAY E MATTHIESSEN, 2004); as relações de intertextualidade (Quais vozes e textos são incluídos no material de análise? Quais foram significativamente excluídos? Como são atribuídas as vozes nos textos? São relatadas diretamente ou indiretamente?); e interdiscursividade (Que discursos são articulados nos textos e como são articulados? Quais recursos linguístico-discursivos caracterizam tais articulações?)

$\mathrm{Na}$ próxima seção, serão apresentadas as análises potencialmente críticas que envolvem problematizações e complexidades ontológicas sobre o corpo da mulher trans nas práticas midiáticas.

\section{Práticas midiáticas, transmulheres: das designa- ções e atribuição de vozes à explanação crítica}

A reportagem jornalística produzida pela Revista Tititi foi veiculada em 2014 e tem duas páginas. O titulo e o subtítulo já orientam o tratamento que será dado ao tema. No título Transex viram rainhas do funk!, há a afirmação e legitimidade da identidade de gênero ao 
usar o item lexical "Transex", reforçado pela identificação valorizada de quem são elas na esfera musical e das celebridades: "rainhas do funk". No subtítulo (Artistas rompem o preconceito e viram fenômeno na internet $e$ nos bailes pelo Brasil), devido ao fato de classificá-las como "artistas" e identificá-las como "fenômeno" popular nacionalmente, o texto as representa de maneira generalizada, com itens lexicais normalmente usados para se referir às celebridades, na prática jornalística. Generaliza-se no subtítulo para se especificar no texto. Interessante perceber que há uma construção léxico-semântica que reforça os propósitos da revista, que é o de publicizar a vida das celebridades em destaque, no momento: rainhas do funk, artistas, fenômeno, internet, bailes pelo Brasil.

Assim como na Revista Tititi, as notícias veiculadas nos sites de informação R7 e G1 representam as funkeiras nos títulos de seus textos ora por meio da categorização classificação (travestis, travestis do Rio) e funcionalização (cantoras), ora pela nomeação e titulação artística (MC Xuxu, MC Transnitta, Mulher Banana), como se observa nos excertos abaixo:

1. Da internet para os palcos: travestis do Rio fazem sucesso e usam o funk para combater preconceito $(R 7)$

2. Travestis rompem preconceitos e fazem sucesso no mundo do funk (G1)

3. MC Xuxu, MC Transnitta e Mulher Banana se consolidam como cantoras. Internet ajuda a fazer com que o trabalho se torne mais conhecido. (G1) subtítulo)

Apesar de os textos representá-las pela desinência feminina, ou mesmo pela nomeação da categoria de gênero, ao usar "Travestis" para se referir e representar as três cantoras, posiciona-as de maneira equivocada, pois apenas a MC Xuxu se autodenomina travesti. Talvez a categorização de isso ou aquilo não importe tanto quando se discute sobre identidades de gênero, como pontua Bento (2015a), mas para o/a leitor/a que julga, avalia e classifica de maneira preconceituosa tais iden- tidades, ou mesmo aquele/a que não tem opinião sobre tal temática ou não percebe a discriminação, como uma forma cruel de exclusão, o uso do item lexical "travestis" para designar pessoas trans, gays, parece-nos ser um grande equívoco, uma simplificação bastante perigosa, que bloqueia ações mais afirmativas, solidárias e menos excludentes (Cf. BHASKAR \& LAWSON, 1998; ARCHER, 2000). O mesmo ocorre na Tititi quando o texto se refere às MC's Xuxu e Trasnitta, como Transex.

Esses dados se conformam aos resultados das pesquisas desenvolvidas por Gomes (2015a; 2015b), Pessoa (2015), Souza e Gomes ${ }^{8}$ (2014), Rodhy e Gomes ${ }^{9}$ (2015): há uma recorrente confusão conceitual nos textos das práticas midiáticas jornalísticas em torno das categorias de gênero que não se enquadram na matriz heterossexual (travesti, transexual, transgênero, homossexual, gays) e os processos que os representam: transexualidade, homossexualidade, transgeneridade, além da dificuldade de se representar a relação entre sexo, gênero e sexualidade. Embora exista um amplo debate (LEITE JR, 2008 citado por OLIVEIRA, 2015, p. 20) acerca da genealogia dessas categorias, é importante pensarmos que cada uma delas "tem uma história específica que se engendra aos contextos sociais e culturais de um dado período", o que não exclui o fato de os textos jornalísticos tratarem do tema com mais acuidade, uma vez que é pela repetição desses atos performativos que nos construímos e nos formamos na vida social (BORBA, 2014).

No excerto 4 extraído da notícia do site G1, observamos tal confusão, pois ali se usa a expressão "artistas homossexuais" como um hiperônimo, ou uma representação coletivizada e homogênea, que abarca as transexuais e travestis, com o objetivo de representar as MC's. Reforçando ainda o uso da desinência masculina em "três deles". Generaliza-se de maneira simplificada e equivocada, para em seguida especificá-las por meio, por exemplo, da nomeação ${ }^{10}$ (Carol Vieira), funcionalização (cantoras e compositoras) e titulação (MC Xuxu):

4. Se durante muito tempo o funk foi considerado um ritmo com profusão de letras homofóbicas, uma geração de artistas homossexuais está disposta a mostrar que o gênero também tem espaço para o público LGBT. Três deles, as cantoras e composito- 
ras Carol Vieira, a MC Xuxu; Camilla Monforte, a MC Transnitta; e Julyanna Barbosa, a Mulher Banana; (G1)

Outro equívoco bastante recorrente, como foi dito, e observado no texto veiculado pelo site G1, trata-se da confusão entre sexualidade, sexo e gênero:

5. Após pedir permissão aos pais para se expor e, consequentemente, acabar revelando a sua sexualidade para toda a vizinhança no programa de rádio, Julyanna começou a ganhar espaço usando o pseudônimo de Garota X. (Mulher Banana) G1

Segundo Louro (2007, p. 11), "a inscrição dos gêneros - feminino e masculino - nos corpos é feita, sempre, no contexto de uma determinada cultura e, portanto, com as marcas dessa cultura." Assim como, "As possibilidades da sexualidade - das formas de expressar os desejos e prazeres..." (p. 11). Ou seja, a nossa formação identitária sociocultural e política, assim como a compreensão dos nossos desejos e prazeres (sexualidade), diferenciam-se do conceito de sexo à luz da biologia (macho e fêmea). Dessa forma, quando o texto refere-se ao conceito de sexualidade como se fosse de transexualidade (a formação da identidade de gênero), acaba levando às pessoas a uma incompreensão de tal categoria. Essas escolhas e inequívocos conceituais podem ser um foco de manutenção política e ideológica da matriz heterossexual, reforçando e acentuando as diferenças sociais, o que leva às situações de vulnerabilidade e exclusão, impedindo, portanto, que as pessoas possam agir de forma diferente na esfera pública, ou mesmo impedindo-as de reconhecer e respeitar os vários gêneros.

Ao narrar sobre a formação de sua identidade de gênero, a Mulher Banana se caracteriza e se descreve a partir de atributos e descrições definidas, bem-humoradas e baseadas no senso comum, e talvez este tom tenha levado a estas confusões, que tenho ressaltado nos excertos anteriores. Ao dizer, a partir de orações relacionais identificacionais, que "era um menino com maria chiquinhas", "a garota $x$ era um personagem", e de circunstâncias "com roupas masculinas", reforçadas pela expressão "tirar a Garota X do armário" (Cf. "sair do armário", expressão própria do universo gay), a Mulher Banana pode ter orientado a leitura e a compreensão do/a jornalista, levando-o/a automaticamente a identificá-la e às outras cantoras, como "artistas homossexuais".

6. "Quando eu comecei a cantar, a minha aparência era masculina ainda, porque eu não tinha certeza de que ia dar certo. Era um menino com maria chiquinhas, com umas roupas engraçadas. A garota $X$ era um personagem que eu colocava só no palco. As pessoas começaram a me reconhecer nas ruas, mesmo trajada com roupas masculinas. Então eu resolvi tirar a Garota $X$ do armário. Foi quando eu comecei a fazer uso de hormônios. Foi acontecendo gradativamente com a minha carreira. Eu cantava de calça, a minha aparência foi mudando, fui colocando uma calça capri e, mais tarde, uma roupa de colegial, que era o meu sonho de infância." (Mulher Banana) G1

No entanto ao narrar a sua transição para o gênero feminino, Mulher Banana, na representação discursiva usada pelo texto, ressalta apenas a transformação em termos de vestuário (calça capri, roupa de colegial) e omite todas as intervenções hormonais e, às vezes cirúrgicas, usadas para feminilizar o corpo, antes masculinizado. Essa omissão tem sido frequente, nos textos jornalísticos, quando a travesti ou a transexual feminina é uma celebridade (Cf. GOMES, 2015a, 2015b), pois não se pontua o sofrimento, mas apenas as possibilidades de alegria e apoio da família. O foco recai no produto/resultado e não no processo com todas as suas contingências e historicidades.

Um dos pontos de destaque dos três textos é a maneira como eles identificam as MC's: representadas pelo nome social feminino - Camilla Monforte, Carol Vieira e Julyanna Barbosa, e pelas desinências femininas (a, elas). Há um reconhecimento e respeito ao gênero feminino, diferentemente de outras notícias e reportagens midiáticas (Cf. SOUZA, GOMES, 2014; GOMES, 2013, GOMES, 2014; GOMES, 2015a; GOMES, 2015b; PESSOA, 2015), que insistem em nomear as identidades trans ainda pelo nome de nascimento, registrado no Cartório Civil. 
7. as cantoras e compositoras Carol Vieira, a MC Xuxu; Camilla Monforte, a MC Transnitta; e Julyanna Barbosa, a Mulher Banana; levam para o público músicas que colocam em pauta os seus dilemas particulares. (G1)

8. Elas estão com tudo e não descem do salto para nada. (Tititi)

9. E Camilla Monforte, 27 anos, a popular MC Transnitta, e Carol Vieira, 26, a também conhecida MC Xuxu conquistaram seu espaço no funk na favela e no asfalto. (Tititi)

10. Anitta se sensibilizaria com a história e anunciaria no Altas Horas, da Globo, que a jovem era a sua única cover oficial. (Tititi)

11. Mas antes de se transformar na MC Xuxu, a gata cantava rap e hip-hop. (Tititi)

12. Com superação e bom humor, funkeiras acumulam fãs e fazem sucesso nas redes sociais. (R7)

Ao designá-las pelo título MC, reforça o respeito e notoriedade das garotas pela função que desempenham no mundo da música: MC Transnitta e MC Xuxu. Dessa forma as categoriza, mas também as nomeia adequadamente ao gênero que se reconhecem. Ao contrário delas, Julyanna, com certa dose de humor, mas também de sensualização, denonima-se como Mulher Banana referindose às mulheres-fruta, também personagens do universo Funk. No entanto, ao se denominar como Mulher Banana, reforça a existência anatômica do corpo masculino, por meio do pênis/banana. São também representadas não só por meio de avaliações positivas e afetivas: a popular, a também já conhecida (epítetos funcionando antepostos ao nome das garotas, qualificando-as positivamente, reforçando o reconhecimento e a legitimidade no universo funk), a jovem, a gata (item lexical afetivo e carinhoso), mas também pelas funções que desempenham no meio artístico: cantoras, funkeiras, compositoras.

O texto da Tititi ainda expande/comenta, por meio de orações relacionais, e identifica/caracteriza para os/ as leitores/as a identidade das cantoras: "que têm no registro nome de homem, mas não o revelam; que são transexuais".

13. As duas (que têm no registro nome de homem, mas não o revelam) já alcançaram milhares de visualizações no YouTube (Tititi)

14. As cantoras, que são transexuais, usam suas canções para levar uma mensagem de diversidade e tolerância por onde passam. (Tititi)

Apesar de destacar que as cantoras não revelam o nome de registro, informação pouco relevante para as questões que englobam o reconhecimento e aceitação das identidades de gênero, ainda assim explora de maneira significativa e explícita o fato de serem transexuais e usarem as músicas de maneira afirmativa: "para levar uma mensagem de diversidade e tolerância por onde passam". Tal tendência e/ou uso é revelador, pois, ao tratá-las desta forma, reforça as ações afirmativas de militância do movimento LGBTs (Lésbicas, Gays, Bissexuais e Travestis), desconstruindo a pedagogia do insulto e os frequentes processos de desumanização, estigmatização e exclusão (MAIO, JUNIOR, 2014, p. 108). Esse uso demonstra reconhecimento do nome social, do ato político de legitimidade de gênero, ou seja, as exigências e direitos conquistados pelo movimento, pois nomear é instituir, inscrever a pessoa nas ações e práticas sociais. Rajagopalan (2003, p. 84), discutindo sobre o uso da designação pela mídia, sustenta que é no uso político de nomes próprios, por meio da designação, que a mídia influencia a opinião pública a favor ou contra personalidades e acontecimentos noticiosos.

Ao representá-las dessa forma, os textos as humanizam, dando ao/a leitor/a detalhes de suas histórias de vida e os motivos que as levaram às práticas de militância por meio do Funk. Observe que as cantoras são chamadas para falar de suas trajetórias e de como se tornaram MC's de sucesso:

15. Camilla, a Transnitta, é brasileira, morou em Lisboa; quando chegou ao Brasil, viu sua vida mudar de cabeça para baixo. Foi expulsa da casa dos 
tios, aos 17 anos, por assumir sua transexualidade. Morou na rua e foi nas imediações da Central do Brasil, no Rio, que conheceu o funk. [...] Ela foi resgatada das ruas por aquele que viria a ser seu primeiro marido e que a levou para morar no Complexo do Alemão. Na comunidade, a cantora começou a imitar os trejeitos de Anitta, o que acabou lhe rendendo o apelido famoso.(Tititi)

A narrativa elaborada pela revista Tititi sobre Transnitta nada difere de outras contadas por travestis, gays, transgêneros, transexuais, entre Outridades: relação causal (por assumir a transexualidade) entre assumir a identidade de gênero (aquela que foge à matriz da heteronormatividade) e a não-aceitação da família, quase sempre de maneira violenta e brutal. Mas as narrativas de vida tanto de Transnitta quanto de MC Xuxu e Mulher Banana são ágeis, ao mesmo tempo em que são elas agentes de suas conquistas e ações (morou, começou a imitar); também são vítimas das ações e práticas dos outros (foi expulsa, foi resgata, a levou), principalmente em relação à afirmação do gênero, pois transgridem a matriz essencialista, biológica e atributiva:

16. "Inclusive cheguei a participar de um concurso para ser cover da Anitta, mas fui desclassificada por ser transex, desabafa”. (Transnitta) Tititi

17. "Eu, que nunca tinha conseguido um emprego por causa do preconceito, de repente estava fazendo shows e conhecendo o Brasil inteiro", lembra. (Transnitta) Tititi

Observe nos excertos 16 e 17 que as circunstâncias, os motivos e/ou causas de não conseguirem empregos são o preconceito e o fato de serem transexuais. Isso é reforçado pelas relações de realce (por ser; por causa do), que estabelecem relação entre a identidade de gênero escolhida (aquela que foge à matriz heterossexual) e o preconceito, ressaltando o cenário de violência a que os LGBTs são submetidos, em todo o país.

A representação discursiva das MC's tem efeitos de autenticidade, pois dá responsabilidade a elas pelo que estão dizendo, mas o fazem de forma atitudinal, por meio de processos mentais: desabafa, lembra e revela. Ao atribuir voz a elas diretamente, os textos geram efeito de engajamento em relação ao que está sendo problematizado pelas funkeiras, pois as vozes sustentam, justificam e fundamentam a proposta da notícia: dar visibilidade ao trabalho das MC's, como se observa nos excertos abaixo:

18. "nos meus shows faço questão de falar que sou transexual, revela Camilla, acrescentando: "se subo no palco é para mostrar que todas nos temos talento".

19. “Já usava minhas letras para desabafar sobre preconceito e a homofobia, mas sempre achei o rap mais sério". (MC Xuxu)

20. "A ideia surgiu quando reparei no aumento de notícias sobre assassinatos de travestis por causa da transfobia”, revela, Xuxu. "Aproveitei a música para mandar o meu recado e principalmente um beijo para quem sofre com a discriminação." (Mc Xuxu)

21. “O meu foco é o público LGBT. Todas as minhas músicas são voltadas para nós. Nas letras eu tento amenizar a homofobia, mostrar a diversidade e tudo o que fale da nossa vida e da minha vida, de uma travesti de 25 anos. Tudo o que eu penso, o que eu vivo eu procuro colocar nas minhas músicas," diz ela.

Nos excertos 18, 19, 20 e 21, há uma recorrência no uso de relações de realce de finalidade (para) na fala das funkeiras, reforçando o posicionamento assertivo e afirmativo delas na compreensão do problema, de forma a refutar, desconstruir e enfrentar as práticas e ações sociodiscursivas intolerantes em relação aos corpos retratados como diferentes: para mostrar que todas nós temos talento; para desabafar sobre preconceito e homofobia e para mandar o meu recado e principalmente um beijo para quem sofre com a discriminação.

$\mathrm{O}$ único texto que apresenta uma voz diferente, além do relato dos /as jornalistas e as vozes das cantoras, é a notícia do G1. Atribui-se voz a um ativista, o coordenador de uma ONG "Rio sem Homofobia”, e 
$\mathrm{o}$ identifica para os/as leitores/as pelo nome próprio e a titulação/função que exerce na ONG, dando-lhe legitimidade e credibilidade. $\mathrm{O}$ que nos chama atenção é a forma como relata o comentário do coordenador, pois, ao fazê-lo, incorre em algumas representações e explicações reducionistas e condensadas. Observemos os excertos abaixo:

22. Para Cláudio Nascimento, coordenador do Rio sem Homofobia, os artistas gays do funk dão visibilidade aos homossexuais que vivem em comunidades e prestam um grande serviço na luta contra o preconceito sexual e racial.(relato do G1)

23. "O funk acaba sendo um grande canal libertário de difusão de informações de combate ao preconceito ao público LGBT. Quando você vê uma transexual ou um gay, você gera uma discussão no grupo, mas também o extrapola, pois o funk tem uma perspectiva muito ampla."E ainda complementa: "A medida que as pessoas veem que há uma travesti, uma transexual cantando funk e que ela poderia ser uma cantora heterossexual e que isso não a faria diferente, que um gay não seria melhor e nem pior do que um cantor hetero, acaba gerando uma visibilidade de que eles podem estar em todos os lugares, inclusive no funk." (voz do coordenador da ONG)

No excerto 22, tem-se uma construção parafrástica, um relato da fala do coordenador da ONG bastante reducionista e simplificada, como se pode observar na construção textual do discurso direto representado em 23, pois o coordenador não afirma que apenas "os artistas gays do funk dão visibilidades aos homossexuais", mas que "A (sic) medida que as pessoas veem que há uma travesti, uma transexual cantando funk que ela poderia ser uma cantora heterossexual e que isso não a faria diferente, que um gay não seria melhor e nem pior do que um cantor hetero, acaba gerando uma visibilidade de que eles podem estar em todos os lugares, inclusive no funk".

$\mathrm{O} / \mathrm{a}$ jornalista, mais uma vez, insere todas as categorias de gênero do LGBTs em uma única categorização/classificação "artistas gays" e ainda o faz de forma preconceituosa, pois classifica os artistas com atributo "gay". Ao fazer tal relação hiperonímica (incluindo no universo gay todas as Outridades), assim, de maneira natural e causal, sugere que artistas gays dão visibilidade apenas às questões homossexuais: "os artistas gays do funk dão visibilidade aos homossexuais que vivem em comunidades", como se o preconceito, a exclusão e as situações de vulnerabilidade fossem apenas relacionadas aos gays, excluindo as Outridades: mulheres trans, homens trans, travestis, lésbicas (BENTO, 2015). Ao fazer isso, o texto desconsidera toda a interpretação da existência constituída e performatizada pelas funkeiras (BORBA, 2014), e cola uma identidade gay a uma identidade trans ou travesti, criando uma "aparente estabilidade corpórea" (BENTO, 2015b).

\section{Considerações finais}

Como reiteram Ramalho e Resende (2011, p. 142143), "a categorização influencia os modos como as pessoas agem e pensam sobre uma dada situação, por isso a preocupação com a questão da classificação é essencial." A forma como os textos midiáticos escolhem as categorizações e classificações identitárias, por meio das designações, principalmente, para representar as Outridades retrata muito as práticas discursivas a que se vinculam, a forma como compreendem tais questões seja pela exclusão, seja pela inclusão. Ao tentar categorizar as cantoras, o G1, principalmente, recorre aos discursos naturalizados do senso comum, ao olhar para as Outridades apenas pelo viés da homossexualidade. Ainda que não sejam aceitos (homossexuais) com a dignidade que lhes é de direto, ainda há uma tolerância no reconhecimento da homossexualidade. Não estou dizendo aceitação social, cultural e política, já que o relativo reconhecimento já não é tão visível em relação às travestis, aos/às transex, aos/às transgêneros.

Como chama atenção Cassal (2015, p. 51), "o desejo sobre o próprio corpo, e em relação a outros corpos, é designado como doença, e um critério para inúmeras violências e violações de direitos". Embora a homossexualidade tenha sido retirada da CID, em 1990 - Classificação Internacional de Doenças -, a transexualidade e a travestilidade permanecem até hoje, registradas como patologias. Bento (2015a), discutindo acerca do 
aprisionamento do gênero como categoria diagnóstica psiquiátrica, afirma que embora no DSM-5 (Manual Diagnóstico de Transtorno Mental) tenham substituído "transtorno de gênero" por "disforia de gênero", e isso seja um motivo de comemoração, ainda assim é preciso problematizar essa mudança em termos culturais e políticos. No entanto, como afirma Cassal (2015, p. 51), "desde a mudança de CID, há inúmeras denúncias de práticas profissionais de 'conversão' de homossexuais, com o suposto objetivo de torná-los heterossexuais". Algumas práticas religiosas apostam na "cura" ou na "prática do exorcismo", como se fosse ainda uma patologia (ou a presença do demônio) o desejo de viver o gênero no qual se reconhece.

As MC's são representadas por nomeações, titulações e identificações relacionais e atributivas. A inclusão das designações femininas e os atributos positivos em relação à construção da identidade celebridade criam de fato um cenário positivo para elas, ainda que se reconheçam e se identifiquem como Travesti (MC Xuxu) e Transexuais (Transnitta e Mulher Banana), embora os textos não consigam fazer uma representação adequada. Essa representação positiva é bastante recorrente neste tipo de gênero: notícia sobre celebridade, artista; ainda mais artistas que têm uma história de superação. Neste caso, as artistas são provenientes de comunidades periféricas, são transviadas/desviantes da matriz heterossexual, e ainda cantam funk, ritmo por si só subversivo.

Essas representações e escolhas lexicogramaticais chamam-nos atenção não só pela performance do gênero, mas também pelo fato de serem cantoras de um ritmo musical subversivo. Além disso, um dos textos foi retirado de uma revista de cunho popular que tem como principal propósito comunicativo dar visibilidade às celebridades das mais diversas áreas artísticas $\mathrm{e}$ culturais. A Tititi caracteriza-se por ser uma publicação de baixo custo, consumida pela massa e por pessoas que querem se informar sobre o mundo público e privado das celebridades (SCALZO, 2003, p. 48). Não se trata de uma mídia de referência, mas feminina, popular, de entretenimento, voltada especialmente para classe C, segundo site da PubliAbril. Ao respeitar e legitimar a identidade de gênero das trans por meio das representações e designações, a revista reforça atitudes positivas de enfrentamento e se alinha aos conteúdos das músicas produzidas por elas. Ao refutar a matriz da heteronormatividade, ao se recusar a reforçar o binarismo, Tititi humaniza o corpo trans, legitima sua afirmação, potencializa a compreensão de gênero como ato político. O mesmo não ocorre com as construções discursivas escolhidas pelas práticas midiáticas do jornalismo on-line dos sites R7 e G1, principalmente.

No que se refere à construção da heterogeneidade textual, tanto a revista quanto o R7 e o G1 dão mais proeminência às vozes das cantoras e dos/das jornalistas; às vezes a mescla de vozes não fica tão evidente. São recorrentes os usos de relações lógico-semânticas de expansão por realce, nas representações discursivas das cantoras, por meio do discurso direto, de forma a qualificar a maneira como o preconceito ocorre, ou mesmo o motivo que levou as cantoras a se inserirem no universo do funk, valorizando temas que tratam as identidades de gênero de maneira mais solidária e afirmativa, por meio de características circunstanciais de causa, modo e condição.

A mediação entre a esfera pública e privada é uma das propriedades das práticas midiáticas, e os impactos desta mediação podem gerar novos realinhamentos, novas formas de interação e novas construções de conhecimentos sobre os mais variados objetos. No entanto, uma construção mais elaborada, mais estudada e mais explanatória sobre as identidades de gênero e as relações que as constituem como sexo, sexualidade e gênero precisam ser repensadas pelas práticas midiáticas jornalísticas de forma que as reduções, simplificações e equívocos observados sejam revistos, a fim de tornar as Outridades menos invisíveis e vulneráveis na esfera pública, porque "a invisibilidade é um modo sutil e extremamente potente de eliminação dos sujeitos considerados como indesejados", e as práticas midiáticas, assim como as ruas, podem ser sim local de visibilidades afirmativas e solidárias. Dessa forma, ao invés de fomentar diálogos e debates qualificados, as práticas midiáticas, em sua grande maioria, estão bloqueando estas oportunidades, ao produzirem antes consumidores/as de fofocas e amenidades ao invés de agentes mais críticos e reflexivos. 


\section{Notas}

1. HALLIDAY,M. A. K.; MATTHIESSEN, C. An introduction to functional grammar. London: Edward Arnold, 2004.

2. Cf. Heberle, V.; MEURER, J. L. (Orgs.). Systemic Functional Linguistics in Action. Revista Ilha do Desterro, Florianópolis, n. 46, jan./jun. 2004.

3. http://www.publiabril.com.br/noticias/1393. Acesso em 17 abr 2015.

4. h t t p : // w w w. jor nalis mo. ufop.br/ criticademidia/?p=1278. Acesso em 17 abr 2015.

5. http://www.abratel.org.br/noticia/rede-recordassociada-da-abratel-completa-60-anos-e-ehomenageada-pelo-congresso-nacional. Acesso em 17 abr 2015.

6. http://redeglobo.globo.com/Portal/institucional/ foldereletronico/g_rs_missao_social.html. Acesso em 17 abr 2015.

7. Discussão apresentada em: GOMES, M. C. A. ; SANT'ANA, M. F. A. construção discursiva de Dilma Rousseff: análise da primeira página de três jornais mineiros à luz dos estudos sistêmico-funcionais. DELTA. Documentação de Estudos em Linguística Teórica e Aplicada (Online), v. 28, p. 515-535, 2012.

8. Cf. SOUZA, D \& GOMES, M.C.A . Corpo transexual na mídia jornalística digital e o olhar do leitor: representações de vulnerabilidade social e diferença na sociedade contemporânea. 2014. (Relatório de pesquisa). Este estudo faz parte de um corpus documental do projeto Corpo na mídia impressa e televisiva: representações de vulnerabilidade social e diferença na sociedade contemporânea, CNPq (PQ2), coordenado pela profa. Dra. Maria Carmen Gomes, e que tem por objetivo principal refletir acerca das relações entre corpo, mídia e diferença.

9. Cf. RHODY, T. \& GOMES, M.C.A. Analisando corpos realinhados e identidades de gêneros em narrativas jornalísticas. 2015. (Relatório de pesquisa). Este estudo faz parte de um corpus documental do projeto Corpo na mídia impressa e televisiva: representações de vulnerabilidade social e diferença na sociedade contemporânea, $\mathrm{CNPq}(\mathrm{PQ} 2)$, coordenado pela profa. Dra. Maria Carmen Gomes, e que tem por objetivo principal refletir acerca das relações entre corpo, mídia e diferença.

10. Estou usando categorias da Representação de atores sociais (RAS) conforme os estudos de Theo van Leeuwen que buscam compreender como os atores sociais podem ser representados em textos, por meio das escolhas sócio-semânticas. (Cf. VAN LEEUWEN, 1997).

\section{Referências bibliográficas}

ARCHER, M.S. Realismo e o problema da agência. Estudos de Sociologia. Rev. do Prog. de Pós-graduação em Sociologia da UFPE. 2000. 6 (2): 51-75.

BHASKAR, R. \& LAWSON, T. Introduction: basic texts and developments. In: ARCHER, M. ET al (Orgs.). Critical Realism. Essential readings. London; New York: Routledge, 1998. p.3-15.

BENTO, B. Determinismo biológico revisitado raça e gênero. Revista Cult. Ano 18. Fev. 2015a. p. 52-55.

É o queer tem pra hoje? Conversando sobre as potencialidades e apropriações da Teoria Queer ao sul do Equador. Entrevista. Áskesis. v.4.n.1.Jan/Jun. 2015. p.143-155.

BIRMAN, J. Guerras PSI. In: Michel Foucault. Revista Cult. N.5. Ano 18. 2015. p. 47

BORBA, R. A linguagem importa? Sobre performace, performatividade e peregrinações conceituais. Cadernos Pagu. n. 43, Campinas. July/Dec. 2014.

BORGERSON, J. Judith Butler. In: SCOTT, J. (org.). 50 Grandes sociólogos contemporâneos. Tradução de Renato Marques de Oliveira. São Paulo, Contexto, 2009.

BUTLER, J. Problemas de gênero. Feminismo e subversão da identidade. Rio de Janeiro: Civilização Brasileira, 2010.

Replantear el universal: La hegemonia y lós limites del formalismo. In BUTLER, J;

LACLAU, E; ZIZEK, S. Contingencia, hegemonía, universalidad: Diálogos contemporâneos en la izquierda. Buenos Aires: Fondo de Cultura Económica, 2011. p. 19-50.

LE BRETON, D. Le corps entre significations et informations. Hermès, La Revue. Vol. 1, n. 68, 2014, p. 21-30.

CASSAL, L.C.B. Medo de que? Revista Sociologia. Ed. 58. Dossiê questões de gênero. Uma abordagem sociológica e sem tabus sobre diversidade, universo trans e homofobia. p.48-55. CÉSAR, M.R.A. 2014. (Des)fazendo gêneros e queerizando a vida: a (des) educação de corpos. In: FERRARI, A. (Org.) Corpo, gênero e sexualidade. Lavras, UFLA, p. 159-174.

COHEN, I. J. Teoria da estruturação e práxis social. GIDDENS, A; TURNER, J. (Orgs).Teoria Social Hoje. São Paulo: Editora Unesp, 1999. P.393-446.

CHOULIARAKI, L. \& FAIRCLOUGH, N. Discourse in late modernity. Rethinking Critical Discourse Analysis. Edinburgh: Edinburgh University Press, 1999. 
Entrevista. Marcia Tiburi. A filósofa vai a guerra. Vestida de Mulher. Revista Cult. Ano 18. Mar. 2015. p. 17-27.

FAIRCLOUGH, N. Critical and Descriptive Goals in Discourse Analysis. Journal of Pragmatics 9. 1985. p.739-763

Media discourse. New York: Edward Arnold, 1995.

Analysing discourse: textual analysis for social research. London; New York: Routledge, 2003.

FAIRCLOUGH, I; FAIRCLOUGH, N. Political discourse analysis. A method for advanced students. London: Routledge, 2012.

FOUCAULT, M. Nascimento da Biopolítica. Curso no Collège de France (1978-1979). São Paulo: Martins Fontes, 2008.

GIDDENS, A. As consequências da modernidade. São Paulo: Editora Unesp, 1991.

GOMES, M.C.A. Eu não me sinto fora do eixo, fora do tom, fora de nada: analisando as construções indentitárias no discurso midiático. Cadernos Discursivos, v. 1, p. 174-188, 2013.

Corpo em Trânsito: Problematizando as Questões de Gênero em Narrativas Jornalísticas. Gláuks. Revista de Letras. Vol.14 N.1 - JAN/JUN 2014. p.1-17.

Sou a travesti da família brasileira: Estudo explanatório-crítico de narrativas jornalísticas e a problematização de gêneros. Revista Calidoscópio. n.2. 2015a. p. 141-152.

GOMES, M.C.A. O Corpo é Meu: Analisando narrativas jornalísticas e o desenquadre do gênero. Revista Agália. 2015b. (no prelo)

HABERMAS, J. Mudança estrutural da esfera pública: investigações quanto a uma categoria da sociedade burguesa. Rio de Janeiro: Tempo Brasileiro, 1962.

HALLIDAY, M. A. K., \& MATTHIESSEN, C. M. I. M. 2004. An Introduction to Functional Grammar (3a ed.). London, Edward Arnold. 667 p.

LARA, G.P; PACHECO, R. Discurso e (des)igualdade social. São Paulo: Contexto, 2015.

LE BRETON, D. Adeus ao corpo: antropologia e sociedade. Campinas, SP: Papirus, 2003.

. A sociologia do corpo. Petrópolis, RJ: Vozes, 2010.

LEITE Jr., J. Nossos corpos também mudam. Sexo, gênero, e a invenção das categorias "travesti"e "transexual" no discurso científico. Tese de doutorado em Ciências Sociais. São Paulo: PUC-SP, 2008.

LOURO, G. P. Pedagogias da sexualidade. LOURO, G. P. (org.) O corpo educado. Pedagogias da sexualidade. 2.ed. 3 reimpressão. Belo Horizonte: Autêntica, 2007. p. 07-34.

MAIO, E.R; JUNIOR, I.B.O. Corpo, gênero, sexualidades e educação. FERRARI, A. (et al.) Corpo, gênero $e$ sexualidade. Lavras: UFLA, 2014. p. 97-118.

OLIVEIRA, M.I.Z. O mundo trans. Conheça um pouco mais a respeito das complexas classificações de gênero que não se enquadram na norma heterossexual. Revista Sociologia. Ed. 58. Dossiê questões de gênero. Uma abordagem sociológica e sem tabus sobre diversidade, universo trans e homofobia. p. 18-23.

PESSOA, D.S. “Eu sou gente!”- Representação d@s (tr@ ns)gêneros em veículos midiáticos - caso Laerte Coutinho. Dissertação de Mestrado. 2015. Programa de Pós-Graduação em Letras do Departamento de Letras e Artes da Universidade Federal de Viçosa.

RAJAGOPALAN, K. Designação: a arma secreta, porém incrivelmente poderosa, da mídia e conflitos internacionais. RAJAGOPALAN, K. Por uma linguística crítica: linguagem, identidade e a questão ética. São Paulo: Parábola Editorial, 2003. p. 81-88.

RAMALHO, V; RESENDE, V.M. Análise de discurso (para a ) crítica: o texto como material de pesquisa. Campinas, SP: Pontes Editores, 2011.

RESENDE, V.M. Análise de discurso crítica e Realismo Crítico. Implicações interdisciplinares. Campinas, SP: Pontes Editores, 2009.

SALIH, S. Judith Butler e a Teoria Queer. Tradução e notas Guacira Lopes Louro. Belo Horizonte: Autêntica, 2012.

SCALZO, M. Jornalismo de Revista. São Paulo: Contexto, 2003.

SOUZA SANTOS, B. A crítica da razão indolente. Contra o desperdício da experiência. São Paulo: Cortez, 2000.

van LEEUWEN, T. A representação dos atores sociais. In: PEDRO, E.R. (Org.) Análise Crítica do discurso. Lisboa: Caminho, 1997. p. 169-222.

Recebido em: 08/07/2015 Aceito em: 15/10/2015 